\title{
Sensitivity analysis of medical centers energy consumption with EnergyPlus
}

\author{
S. Rastegarpour, L. Ferrarini \\ Dipartimento di Elettronica, \\ Informazione e Bioingegneria, \\ Politecnico di Milano, \\ Milano, Italy \\ soroush.rastegarpour@polimi.it \\ luca.ferrarini@polimi.it
}

\author{
Rosalia Pacheco-Torres \\ Departamento de Ingeniería Civil, \\ Construcción, Infraestructura y \\ Transporte, \\ Universidad Politécnica de Madrid \\ Madrid, Spain \\ rosalia.pacheco@upm.es
}

\author{
A. Kalogeras, C. Koulamas \\ Industrial Systems Institute \\ Research Centre ATHENA \\ Patras, Greece \\ kalogeras@isi.gr, \\ koulamas@isi.gr
}

\begin{abstract}
Sensitivity analysis plays a vital role in building energy analysis. It is done to clarify which are the crucial variables affecting building thermal performance and to evaluate quantitatively those effects. It can be conducted both through energy simulation models and real case observations. The present paper is devoted to the description of the sensitivity analysis techniques that are able to extract the most effective parameters on the energy consumption of a commercial building, particularly medical centers. Energy consumption in medical centers, generally, depends on several parameters ranging from technical and geometrical aspects to climatic conditions. This paper is focused on the application of sensitivity analysis in term of energy consumption in medical centers through a benchmark simulation model which is developed by National Renewable Energy Laboratory (NREL) in order to classify the most effective parameters on energy consumption of a large hospitals.
\end{abstract}

Keywords-Sensitivity analysis, Energy-Plus simulation models, Medical centers, Energy saving

\section{INTRODUCTION}

The current pressure to a general containment of energy consumption is clearly shaping the way new buildings are constructed and operated, but also is affecting the retrofitting of existing buildings. As a matter of fact, given the age of the building stock in most countries, energy retrofit arises as one of the main tools for meeting the energy saving requirements. Estimating buildings consumption and above all estimating the effect of an intervention beforehand is important for achieving building investment efficiency. In the present paper, we focus on energy consumption in hospitals and medical centers, with the general goal to identify and evaluate the impact of the most important factors affecting the overall energy consumption. The identified tools should help energy service companies in evaluating their own investment decisions.

Sensitivity analysis is an activity devoted to understand the impact of a parameter over a cost function. The easiest way to perform it is through simulation, provided that we start from a reliable model. As shown in the technical literature [1] [2] [3] [4], many different approaches can be adopted for energy modelling of buildings. Black box model is known as purely data driven model. Statistical models are directly applied to capture the correlation between building energy consumption and operation data. This type of models needs on-site measurements over a certain period of time to train the models to be able to predict the building operation under different conditions. These black box models are also widely applied in existing studies to determine building control strategies to reduce energy consumption and energy cost [5] [6].

A class of models is derived through the physical approach (equations from conservation laws) [3] [7]. They allow to start from some physical parameters and quantities of the building and of the technological plants and to arrive to an estimation of energy consumption. An example of a wide-spread simulation environment is EnergyPlus, developed in the USA as a joint effort of different entities (the National Renewable Energy Laboratory, the U.S. Department of Energy National Laboratories, academic institutions, and private companies) [3]. This tool allows to emulate a hospital energy behaviour with high level of details, in different climatic zones and with different plants. Another example is based on international standards, like the ISO 13790, which provides methods for the assessment of the annual energy needed for space heating and cooling in residential or non-residential buildings, based on quasi-static models [8].

On the other hand, when more data from the building are available, it is possible to look for correlations among them, and so design black-box prediction models and machine learning techniques [1] [9] [10]. They allow to extrapolate interpretative models from data and draw some conclusions.

The present work is devoted to perform sensitivity analysis on energy consumption in hospitals and medical centres through the help of EnergyPlus simulation environment and tools.

The paper is organized as follows. In Section 2 the EnergyPlus modelling and simulation environment is briefly described. In section 3 , the available models are described, while in section 4, a first modeling analysis and comparison is done. Section 5 describes the sensitivity analysis. Finally, conclusions are given in section 6. 


\section{ENERgyPlus}

EnergyPlus is a powerful tool for simulation of large buildings' energy consumption and generation of data for further analysis which is developed in collaboration with the National Renewable Energy Laboratory (NREL), various U.S. Department of Energy (DOE) National Laboratories, academic institutions, and private firms [11]. It is an open-source and free simulation software that engineers and researchers use to simulate the buildings electrical and gas energy consumption in the context of both technical equipment for heating, cooling, ventilation, lighting (including external and internal lighting), and plug and process loads and physical aspects such as the materials and dimension according to the weather condition [12] [13].

Technical Support Document (TSD) is a report which is developed by national renewable energy laboratory to prepare the procedure and methodology for the development of Advanced Energy Design Guide for Large Hospitals (AEDG-LH) and its simulation in the Energy-Plus software. The virtual hospital which is designed in AEDG-LH is a model of a large building of $427,173 \mathrm{ft}^{2}\left(39685.67031 \mathrm{~m}^{2}\right), 7$ floors in which floor-to-ceiling height is $9 \mathrm{ft}(2.7432 \mathrm{~m})$ and floor-to-floor height is: $14 \mathrm{ft}$ in diagnostic and treatment areas in floor 2 and $13 \mathrm{ft}$ in all other areas in floors 1, 3 and 7 . The model includes 104 separate zones as distinct thermal zones [12] [14].

\section{AVAilable Models In EnERgyPlus}

There are two main models of large hospitals with regard to energy consumption [12]:

1) Baseline model

The baseline model is developed by applying the criteria of the Standard 90.1-2004 to the prototype model.

2) Low-Energy models

Many energy efficient technologies are used in these models such as: high efficiency System Water Heating (SWH), reduced interior lighting power density and high efficiency HVAC systems. Low-Energy model can be divided into three different models according to the HVAC system:

a) Advanced Variable Air Volume System (VAV) system with separate outdoor air treatment (Advanced VAV). In this system, the outdoor air is separately conditioned to set point $\left(50^{\circ} \mathrm{F}\right)$ before being mixed with the return air. It will minimize zone reheat coil energy

b) Fan coil unit system with a Fan Coil Unit Dedicated Outdoor Air System (FCU DOAS). This system is modeled with water preheat coil, water cooling coil and variable air volume fan.

c) Water Source Heat Pump (WSHP) system with a Dedicated Outdoor Air system (DOAS). This system has a heat pump for cooling and heating, a heat pump for extracting the energy of each zone and a boiler and cooler to maintain the loop temperature.

According to the proposed models, many parameters should be changed in order to obtain 50\% energy saving in the Low-Energy models in comparison to baseline model. Table1 lists the main fields to specify which part is changed with respect to the models.

Once the basic differences between the four models have been explored, the effect of climatic conditions is investigated (related to the location of the building). Differences between the same model (for example baseline model) are explored but with reference to different climate zones.

To study the effect of climatic conditions, the models of 7 cities are compared. Each of these cities correspond to existing climatic zones in USA [15]. These locations are depicted in Fig. 1 and the relationship between building American climatic zones and the International Energy Conservation Code (IECC) is shown in TABLE 2.

TABLE 1: Fields That Change With Respect To The Models

\begin{tabular}{|c|c|c|c|c|c|}
\hline & & \multicolumn{4}{|c|}{ MODEL } \\
\hline & & Baseline & $\begin{array}{l}\text { Low energy } \\
\text { VAV }\end{array}$ & $\begin{array}{l}\text { Low energy } \\
\text { Fancoil }\end{array}$ & $\begin{array}{l}\text { Low energy } \\
\text { Heat Pump }\end{array}$ \\
\hline \multirow{2}{*}{$\begin{array}{l}\text { Building } \\
\text { elements }\end{array}$} & materials & Yes & \multicolumn{3}{|c|}{$\begin{array}{l}\text { Yes, but is the same for all Low energy models } \\
\text { of the same location }\end{array}$} \\
\hline & window & Yes & \multicolumn{3}{|c|}{$\begin{array}{l}\text { Yes, but is the same for all Low energy models } \\
\text { of the same location }\end{array}$} \\
\hline $\begin{array}{l}\text { Energy } \\
\text { Consumption }\end{array}$ & Internal gains & yes & \multicolumn{3}{|c|}{$\begin{array}{l}\text { Yes, but is the same for all Low energy models } \\
\text { of the same location }\end{array}$} \\
\hline \multirow{6}{*}{$\begin{array}{l}\text { Instrument } \\
\text { equipment }\end{array}$} & Coils & yes & yes & yes & yes \\
\hline & Pumps & yes & \multicolumn{2}{|c|}{$\begin{array}{l}\text { Yes, but is the same for VAV } \\
\text { and Coil model }\end{array}$} & yes \\
\hline & Controllers & yes & yes & yes & yes \\
\hline & Fans & yes & yes & yes & yes \\
\hline & HVAC design objects & yes & yes & yes & yes \\
\hline & Zone Air Flow & yes & \multicolumn{3}{|c|}{$\begin{array}{l}\text { Yes, but is the same for all Low energy models } \\
\text { of the same location }\end{array}$} \\
\hline Set points & Set points & yes & yes & yes & yes \\
\hline
\end{tabular}




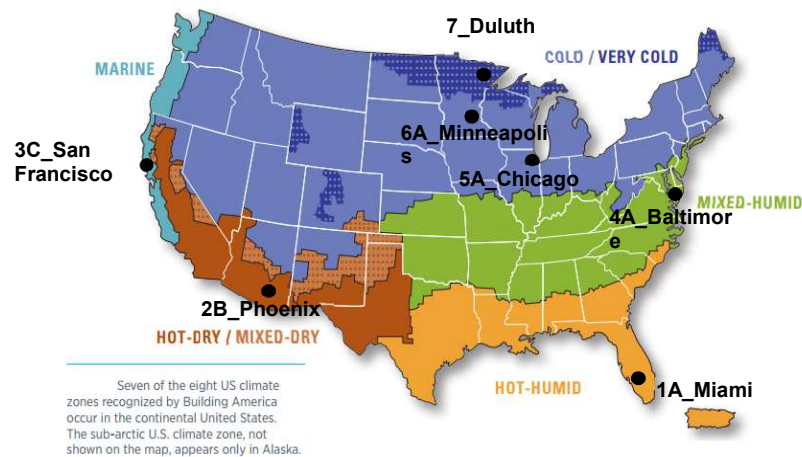

Fig. 1. Location of the cities studied

TABLE 2. RELATIONSHIP BETWEEN BUILDING AMERICAN CLIMATIC ZONES AND THE IECC.

\begin{tabular}{|c|c|c|}
\hline City & US climatic zone & IECC climatic zone \\
\hline Miami & Hot humid & $\begin{array}{c}\text { 2A and 3A } \\
\text { counties below } \\
\text { warm-humid line }\end{array}$ \\
\hline Phoenix & Hot dry / mixed dry & Zone 3B / Zone 4B \\
\hline San Francisco & Marine & $\begin{array}{c}\text { All counties with } \\
\text { a "C" moisture } \\
\text { regime }\end{array}$ \\
\hline Baltimore & Mixed humid & $\begin{array}{c}\text { 4A and 3A } \\
\text { counties above } \\
\text { warm-humid line }\end{array}$ \\
\hline Chicago & Cold (with coast) & Zones 5 and 6 \\
\hline Minneapolis & Cold & Zones 5 and 6 \\
\hline Duluth & Very Cold & Zone 7 \\
\hline & \multicolumn{2}{|c}{} \\
\hline
\end{tabular}

These cities cover different climate zones. Building description (area, schedules, materials and equipment) is the same for all climate zones. Inputs and outputs that change according to different climatic zones are listed in TABLE 3.

TABLE 3. INPUTS AND OUTPUTS THAT CHANGE ACCORDING TO DIFFERENT CLIMATIC ZONES

\begin{tabular}{|c|c|c|c|c|c|}
\hline & & \multicolumn{4}{|c|}{ MODEL } \\
\hline & & Baseline & $\begin{array}{l}\text { Low energy } \\
\text { VAV }\end{array}$ & $\begin{array}{l}\text { Low energy } \\
\text { Fan Coil }\end{array}$ & $\begin{array}{l}\text { Low energy } \\
\text { Heat Pump }\end{array}$ \\
\hline $\begin{array}{l}\text { Building } \\
\text { description }\end{array}$ & $\begin{array}{l}\text { Wall and Roof insulation } \\
\text { layer thickness }\end{array}$ & Yes & \multicolumn{3}{|c|}{$\begin{array}{l}\text { Yes, but is the same for all Low energy } \\
\text { models of the same location }\end{array}$} \\
\hline \multirow{7}{*}{$\begin{array}{l}\text { Results: Energy } \\
\text { Consumption }\end{array}$} & Interior lighitng & No & \multicolumn{3}{|c|}{$\begin{array}{l}\text { Yes, but is the same for all Low energy } \\
\text { models of the same location }\end{array}$} \\
\hline & Exterior lighting & No & \multirow{3}{*}{\multicolumn{3}{|c|}{$\begin{array}{l}\text { Fixed value for all the locations (reduced } \\
\text { compared to baseline model) }\end{array}$}} \\
\hline & Interior equipment & No & & & \\
\hline & Exterior equipment & No & & & \\
\hline & Others & Yes & Yes & Yes & Yes \\
\hline & Cooling & Yes & Yes & Yes & Yes \\
\hline & Heating & Yes & Yes & Yes & Yes \\
\hline
\end{tabular}

According to the simulation results of AEDG-LH virtual hospital by EnergyPlus simulator, we can conclude that:

- Energy consumption in both electrical and gas equipment is decreased in Low-Energy models.

- Fans, pumps and motor efficiency are increased in the Low-Energy models which results in increased efficiency and energy saving. 


\section{MODELING ANALYIS AND COMPARISON}

In the following tables, the breakdown of energy costs in 3 models of large hospitals are represented as simulated by EnergyPlus in different climatic zones.

TABLE 4. BREAKDOWN OF ENERGY COSTS

\begin{tabular}{|c|c|c|c|}
\hline & \multicolumn{3}{|c|}{ Baseline model } \\
\hline & Hot & Humid & Cold \\
\hline Heating(natural gas[GJ]) & $25.33 \%$ & $29.67 \%$ & $30.66 \%$ \\
\hline Cooling(Electricity[GJ]) & $12.94 \%$ & $9.9 \%$ & $9.29 \%$ \\
\hline Interior Lighting(Electricity[GJ]) & $13.14 \%$ & $13.24 \%$ & $13.24 \%$ \\
\hline Exterior Lighting(Electricity[GJ]) & $3.13 \%$ & $3.16 \%$ & $3.16 \%$ \\
\hline Interior Equipment(Electricity[GJ]) & $13.92 \%$ & $14.04 \%$ & $14.03 \%$ \\
\hline Exterior Equipment(Electricity[GJ]) & $1.32 \%$ & $1.335 \%$ & $1.335 \%$ \\
\hline Others(Electricity[GJ]) & $30.19 \%$ & $28.57 \%$ & $28.27 \%$ \\
\hline
\end{tabular}

\begin{tabular}{|c|c|c|c|}
\hline & \multicolumn{3}{|c|}{ Low energy model (Heat Pump) } \\
\hline & Hot & Humid & Cold \\
\hline Heating(natural gas[GJ]) & $1.6 \%$ & $2.28 \%$ & $3.57 \%$ \\
\hline Heating(Electricity[G]]) & $0.6 \%$ & $0.86 \%$ & $0.916 \%$ \\
\hline Cooling(Electricity[GJ]) & $21.08 \%$ & $13.92 \%$ & $11.68 \%$ \\
\hline Interior Lighting(Electricity[G]]) & $13.91 \%$ & $16.7 \%$ & $15.63 \%$ \\
\hline Exterior Lighting(Electricity[G]]) & $1.92 \%$ & $2.305 \%$ & $2.17 \%$ \\
\hline Interior Equipment(Electricity[G]]) & $21.525 \%$ & $25.87 \%$ & $24.34 \%$ \\
\hline Exterior Equipment(Electricity[GJ]) & $0.57 \%$ & $0.685 \%$ & $0.64 \%$ \\
\hline Others(Electricity[GJ]) & $39.66 \%$ & $37.18 \%$ & $41.03 \%$ \\
\hline & \multicolumn{3}{|c|}{} \\
\hline & \multicolumn{3}{|c|}{ Low energy model (VAV) } \\
\hline Heating(natural gas[GJ]) & $3.935 \%$ & Humid & Cold \\
\hline Cooling(Electricity[G]]) & $16.975 \%$ & $7.46 \%$ & $12.843 \%$ \\
\hline Interior Lighting(Electricity[G]]) & $13.71 \%$ & $10.87 \%$ & $10.5 \%$ \\
\hline Exterior Lighting(Electricity[G]]) & $1.89 \%$ & $15.765 \%$ & $14.143 \%$ \\
\hline Interior Equipment(Electricity[G]]) & $21.17 \%$ & $2.18 \%$ & $1.963 \%$ \\
\hline Exterior Equipment(Electricity[GJ]) & $0.56 \%$ & $24.43 \%$ & $21.973 \%$ \\
\hline Others(Electricity[GJ]) & $41.77 \%$ & $0.645 \%$ & $0.58 \%$ \\
\hline
\end{tabular}

Generally, there are no any noticeable differences between energy consumption related to two Low-Energy models. In all these models the heating system has the lowest energy consumption in comparison to other sections. For instance, the share of energy consumption of the heating system in the Heat-Pump model is at least $2.2 \%$ in hot climates and maximum of $4.5 \%$ in cold weather condition.

On the other hand, cooling system and interior equipment cover a significant portion of total energy consumption in hospitals, so that cooling energy consumption is between $11.6 \%$ and $21.08 \%$ in cold and hot climate respectively and interior equipment consume $21.5 \%$ to $24.34 \%$ of total energy in hot and cold climate respectively.

Interior lighting equipment has greater energy consumption in comparison to exterior ones such that interior lighting devices consume $13.5 \%$ to $15.6 \%$ of total energy.

Unlike Low-Energy models, in the baseline model most of the contribution of energy consumption is related to heating and cooling system. According to the baseline model, the energy consumption of different fields are the same in different climate zones. For example, the interior equipment has about $14 \%$ of contribution of total energy consumption in all of weather conditions.

Table 5. ENERGY SAVING IN LOW-ENERGY MODELS IN COMPARISON TO BASELINE MODEL

\begin{tabular}{|c|c|c|c|}
\hline & \multicolumn{3}{|c|}{ CUMATICZONE } \\
\hline BASELNEMODEL & Hot & Humid & Cold \\
\hline Energy Per Total Building Area [MJ/m2] & $2,534.00$ & $2,536.45$ & $2,550.13$ \\
\hline Heating (Natural Gas [G]]) & $24,465.13$ & $28,390.26$ & $29,356.09$ \\
\hline Cooling (Electricity [G]]) & $12,462.42$ & $9,553.70$ & $8,891.74$ \\
\hline Interior Lighting (Electricity [G]]) & $12,677.03$ & $12,677.03$ & $12,677.03$ \\
\hline Interior Equipment (Electricity [G]]) & $13,433.53$ & $13,433.53$ & $13,433.53$ \\
\hline Others * (Electricity [G]]) & $29,132.02$ & $27,336.45$ & $27,065.55$ \\
\hline LOW ENERGY ADVANCED VAV MODEL & \multicolumn{2}{|c|}{ ENERGY SAVINGS(Compared to baseline) } \\
\hline Energy Per Total Building Area & $41.50 \%$ & $50.00 \%$ & $46.67 \%$ \\
\hline Heating & $91.00 \%$ & $87.00 \%$ & $76.00 \%$ \\
\hline Cooling & $22.50 \%$ & $43.00 \%$ & $35.33 \%$ \\
\hline Interior Lighting & $38.00 \%$ & $38.50 \%$ & $38.67 \%$ \\
\hline Interior Equipment & $10.00 \%$ & $10.00 \%$ & $10.00 \%$ \\
\hline Others * & $17.50 \%$ & $29.00 \%$ & $22.67 \%$ \\
\hline LOW ENERGY HEAT PUMP MODEL & \multicolumn{1}{|c|}{ ENERGY SAVINGS(Compared to baseline) } \\
\hline Energy Per Total Building Area & $40.50 \%$ & $48.50 \%$ & $46.00 \%$ \\
\hline Heating & $98.50 \%$ & $96.00 \%$ & $93.67 \%$ \\
\hline Cooling & $4.50 \%$ & $31.00 \%$ & $34.67 \%$ \\
\hline Interior Lighting & $38.00 \%$ & $38.50 \%$ & $38.67 \%$ \\
\hline Interior Equipment & $10.00 \%$ & $10.00 \%$ & $10.00 \%$ \\
\hline Others * & $23.50 \%$ & $34.50 \%$ & $24.33 \%$ \\
\hline
\end{tabular}


In total, the use a Low-Energy model instead of baseline model will result in about $90 \%$ energy saving in heating, $38 \%$ energy saving in interior lighting, $10 \%$ energy saving in interior equipment. For the cooling system there will be about $35 \%$ energy saving in both humid and cold climates while it will be about $10 \%$ for hot climates.

Aggregating the energy consumption costs, they can be divided to two sections including heating-cooling systems and other equipment. According to this point of view, other equipment has significant contribution in comparison to heating and cooling systems in both baseline and Low-Energy models. According to energy plus simulation results, the following results can be obtained:

TABLE 6. CONTRIBUTION OF ENERGY CONSUMPTION IN HVAC SYSTEM AND OTHER PARAMETERS - BASED ON LOW ENERGY MODELS
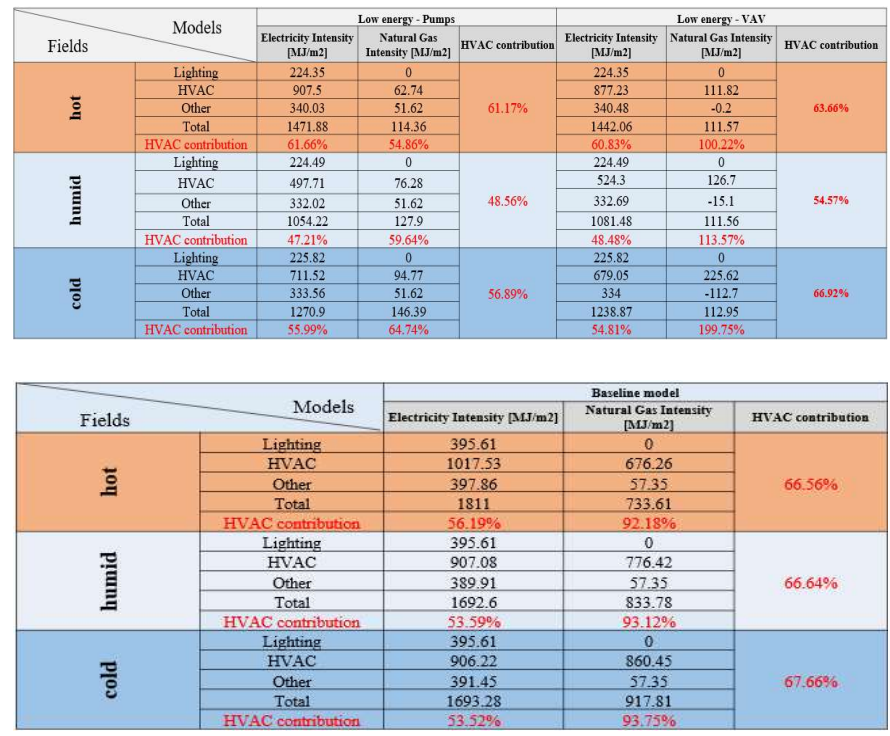

Summarizing the above analysis, we can claim the following general conclusions:

A) Main costs breakdown

- In the baseline model:

- About $40 \%$ of total energy consumption is related to heating and cooling system.

- About $60 \%$ of total energy consumption is related to other equipment

- In the Low-Energy models:

- About $20 \%$ of total energy consumption is related to heating and cooling system.

- About $80 \%$ of total energy consumption is related to other equipment

B) Lighting costs

- It's about $17 \%$ of the overall consumption, for every model

C) Interior equipment

- In the base line model: $14 \%$ of the overall consumption

- In the Low-Energy models: $24 \%$ of the overall consumption

As for savings of Low-Energy models with respect to the baseline model:

- $40 \%$ to $50 \%$ of total energy $/ \mathrm{m}^{2}$.

- $40 \%$ on lighting

- $\quad 90 \%$ on conditioning

\section{SENSITIVITY ANALYSIS}

This chapter discusses sensitivity analysis conducted to show the effect of each parameter in the energy consumption. A list of effective parameters on the energy consumption is summarized in the TABLE 7. 
TABLE 7. MOST EFFECTIVE PARAMETERS ON THE ENERGY CONSUMPTION

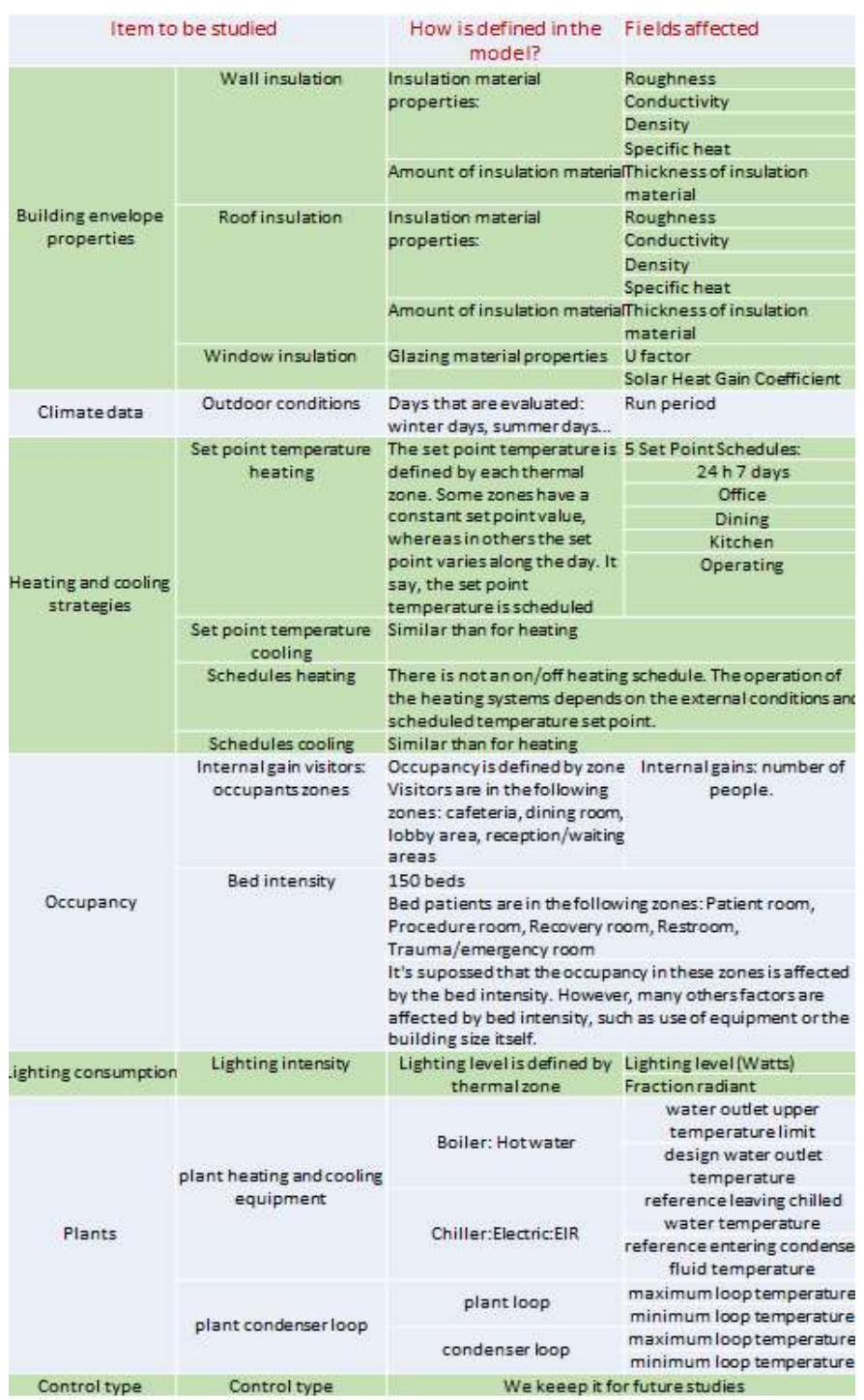

\section{A. Sensitivity towards climatic zones}

Once the main effective parameters have been identified in the model TABLE 7, a sensitivity analysis is conducted to assess the real effect on the final energy consumption of the building.

The same model is evaluated under different climatic conditions according to the seven locations of TABLE 2.

As can be seen from Fig. 2, energy demand for equipment (interior and exterior) and lighting (interior and exterior) remains the same in all the locations. At some extent, this could make sense. The electric and lighting equipment is the same for every location, as well as the occupancy schedules. Given that it's a baseline model, there are no special daylighting sensors to reduce lighting needs depending on outdoor lighting.

From Fig. 3, notice that both exterior lighting and exterior equipment energy demand is reduced compared to baseline model. Compared to the baseline model, interior equipment energy demand is reduced $10 \%$ compared to baseline model. As well as for the baseline model, energy demand for lighting (interior and exterior) and equipment (interior and exterior) are the same for all the zones. 


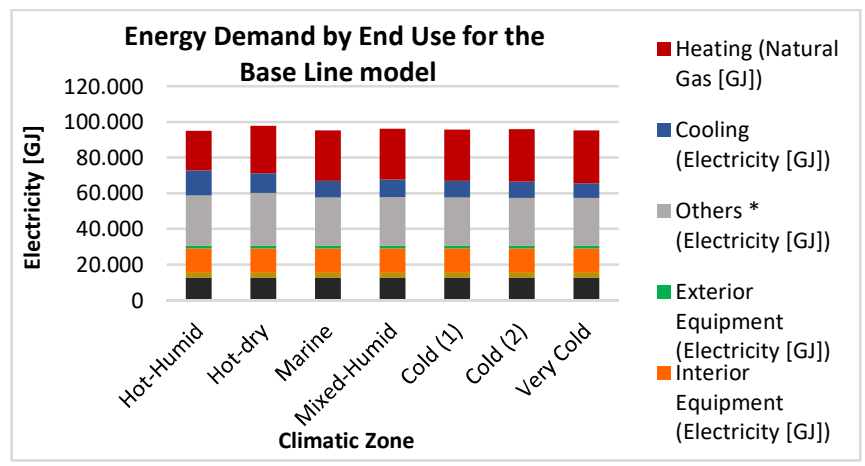

Fig. 2. Sensitivity analysis with respect to climate zones for baseline model

Fig.4 and Fig.5, evidence that interior lighting changes from one climatic zone to other, as a consequence of the different natural radiation levels from one location to another. However, energy demand for exterior lighting, interior equipment and exterior equipment remains the same for all the locations (the same for the other LowEnergy models), as these consumptions are more related to the use habits of the building than to the climatic conditions.

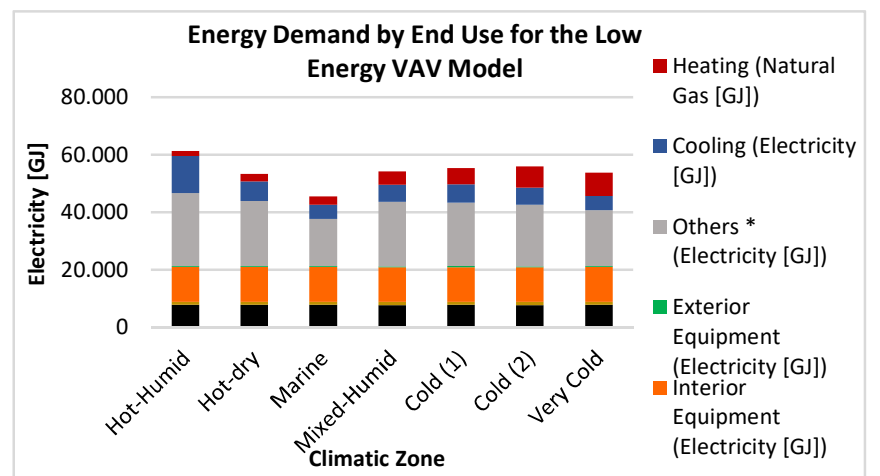

Figure 3: Sensitivity analysis with respect to climate zones for VAV Low-Energy model.

From Fig. 2, Fig.3, Fig.4 and Fig.5, it can be concluded that:

- Baseline Model: energy demand for equipment (interior and exterior) and lighting (interior and exterior) remains the same in all the locations

- Low-Energy Models: exterior lighting, interior equipment and exterior equipment demand do not depend on the location and are a fixed value for the 3 models in all the locations.

- Low-Energy Models: interior lighting does not change from one Low-Energy model to another, but changes according to the location.

- Low-Energy Models: \% of energy saved by end use is quite constant for all the Low-Energy models, except for heating and cooling.

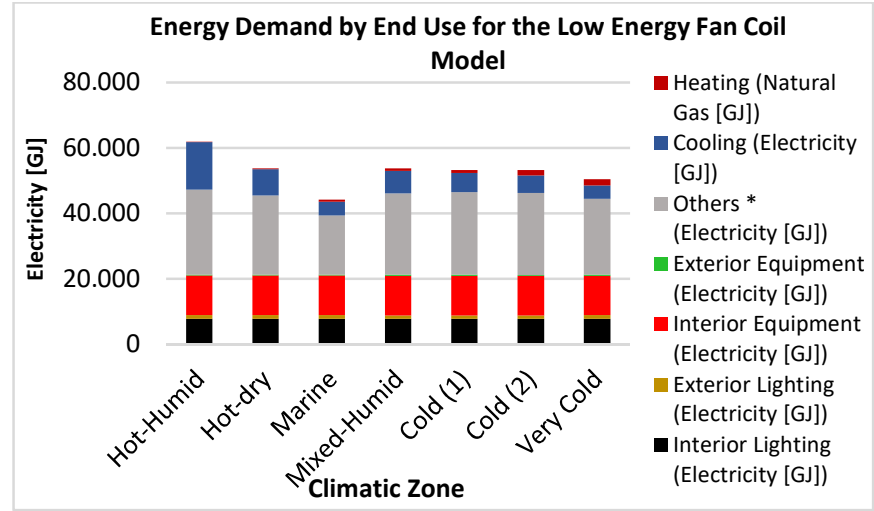

Fig. 4. Sensitivity analysis with respect to climate zones for Fan-Coil Low-Energy model 


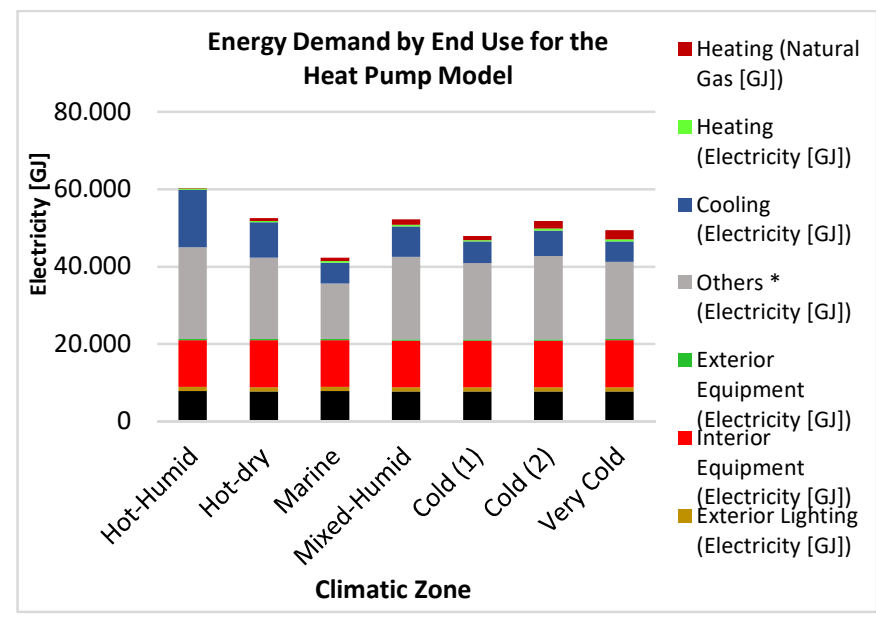

Figure 5: Sensitivity analysis with respect to climate zones for Heat-Pump Low-Energy model

The main conclusions obtained from the sensitivity analysis towards climatic zones are:

- In the sense of construction and sizing: there is no significant differences between baseline model and Low-Energy models. The only noticeable difference could be the increasing in thickness of insulation layer and decreasing in some parameters like Heat Transfer Coefficient (U-coefficient) of windows in the Low-Energy model.

- $\quad$ Electric energy consumption in lights, electric equipment and gas equipment is decreased in Low-Energy models.

- Fans, Pumps and motor efficiency are increased in the Low-Energy model which result in more efficiency and energy saving.

- The most influential parameter set is the structure and technology of the HVAC systems among Low-Energy models (VAV-Pump-Coil)

\section{B. Sensitivity towards thermal plant main parameters}

Plants loops have some control for the correct operation of the loop. Each plant loop includes several technical equipment which follow the control commands coming from controllers. The performance of these equipment is strongly dependent on the set-points of control loops. To realize the effect of each plant equipment, a sensitivity analysis has been done based on the set-points variation. According to the sensitivity analysis done the following results can be listed (Fig.6 and Fig.7):

- Gas energy demand: A dramatic downward trend in heating energy consumption according to setpoint reduction

- Electrical energy demand in the cooling and heat rejection: A downward trend according to setpoint reduction.

- Electrical energy demand in the fans and pumps: It is remaind relatively constant.

- Electrical energy demand in the humidification: It has dramatically increased.

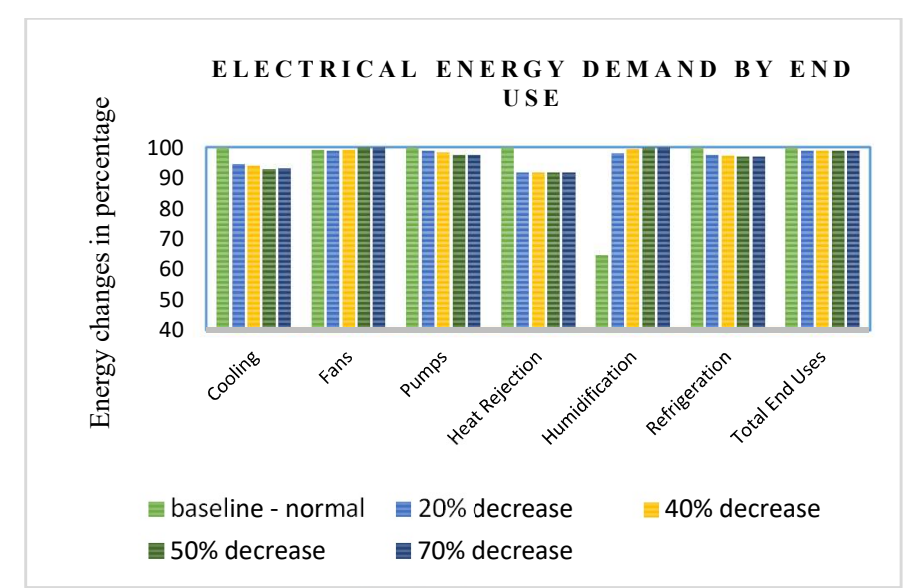

Fig. 6. Sensitivity analysis according to the plant equipment Properties-Electrical energy demand - Setpoint reduction of heating system. 


\section{Sensitivity towards occupancy}

According to common knowledge, the expected impact of changes in occupancy is many-fold. On one hand, the resulting changes of internal thermal gains are expected to decrease heating and increase cooling requirements - and thus the respective energy consumption components. On the other hand, people inside a space interact in many ways with the building systems, such as changing the heating/cooling set-points (if allowed), changing infiltration figures by acting mainly on windows (if allowed), changing the lighting usage patterns (if allowed or if occupancy sensor based lighting is used), changing the ventilation requirements and usage pattern (if Demand Controlled Ventilation - DCV is being used), as well as changing the electricity consumption usage patterns, either by changing the hospital laboratory and medical examination equipment (e.g. MRI) usage patterns or by acting on smaller miscellaneous electrical equipment and devices, which, in turn, affect also internal heating and cooling loads, besides the direct electrical consumption, thus closing a very complex loop of interactions. As most of the above aspects are mainly handled using scheduled inputs by dynamic simulators such as EnergyPlus, the analysis presented in this part focuses on the effects over the heating and cooling internal gains, requiring other, externally produced knowledge (e.g. by statistical processing of real measured data) in order to extract correlations between changes of base occupancy figures and resulting simulator inputs.

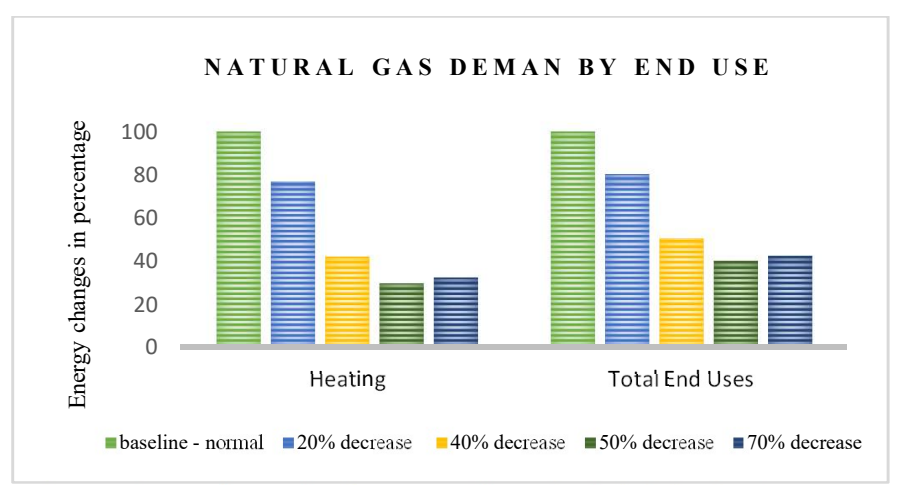

Fig. 7. Sensitivity analysis according to the plant equipment Properties-Gas energy demand-Setpoint reduction of heating system.

According to the conducted analysis following results can be concluded:

- Gas energy demand: A slight downward trend in heating energy consumption with the increase in number of visitors

- Electrical energy demand in the cooling system: A slight increase by increasing the number of visitorss.

- Electrical energy demand in the fans: It has remained fairly stable with the increase in number of visitors.

- Electrical energy demand in the pumps: A slight increase with the increase in number of visitors.

- Electrical energy demand in the humidification: Dramatically decrease due to increase in number of visitors.

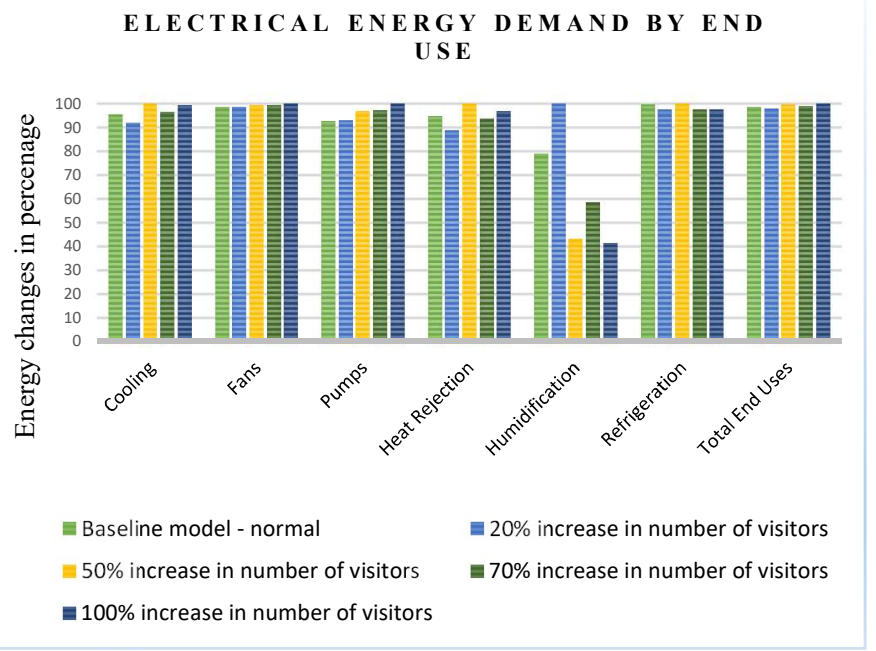

Fig.- 8. Sensitivity analysis according to occupancy - Electrical energy demand - upward trend of number of visitors 


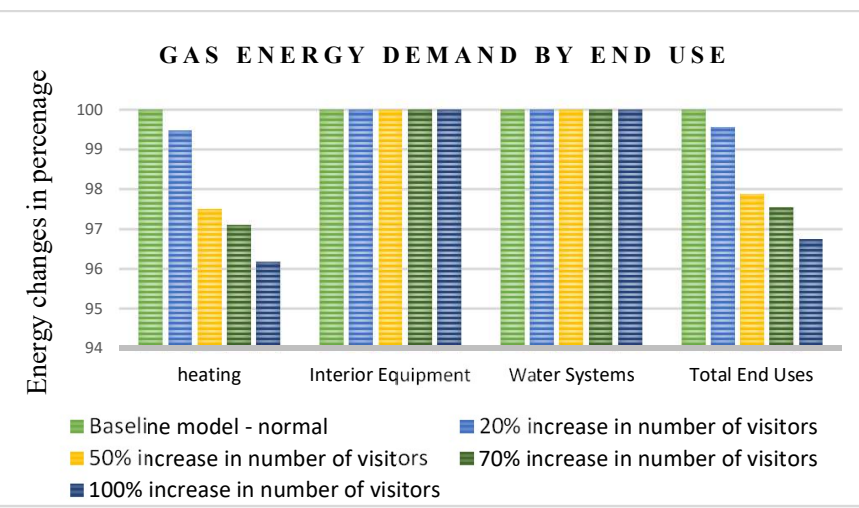

Fig. 9. Sensitivity analysis according to occupancy - Gas energy demand - upward trend of number of visitors

\section{CONCLUSION}

The present paper focuses on energy behaviour of hospitals and medical centers, and in particular it investigates the impact of the main parameters and variables on the total energy consumption. The sensitivity analysis has been done through the help of a well-known reliable simulation environment, namely EnergyPlus, which also provides a set of comprehensive parametric model of large hospitals, including a baseline model and three energy-efficient models.

Through a wide experimental campaign on those models, the impact of climatic zones, occupancy, plant parameters are evaluated and those effects are compared between baseline and efficient models. Results are quite generic, although may vary from hospital to hospital due to the adoption of some new technology or to some specific peculiarity.

Future directions include acquiring data and information on some real hospital and comparing the simulation results with real data.

\section{ACKNOWLEDGMENT}

This research was partially by the buropean

Commission H2020-MSCA-RISE-2014, grant no. 645694 (research project STEER).

\section{REFERENCES}

[1] S. Karatasou, M. Santamouris and V. Geros, "Modeling and predicting building's energy use with artificial neural networks: Methods and results," Energy and Buildings, vol. 38, no. 8, p. 949-958, 2006.

[2] W. Shengwei, C. Yan and F. Xiao, "Quantitative energy performance assessment methods for existing buildings," Energy and Buildings - ELSEVIER, vol. 55, p. 873-888, 2012.

[3] U. o. Energy, "Energy Simulation Software: About Energy Plus," Office ofenergyefficiency andrenewableenergy, 3 March 2014. [Online]. Available: http://www.energyplus..

[4] D. B. Crawleya, J. Handb, M. Kummertc and B. Griffithd, "Contrasting the capabilities of building energy performance simulation programs," Building and Environment - ELSEVIER, vol. 43, no. 4, p. 661-673, 2008.

[5] Y. Kyungtae, L. Rogelio, J. M. Pedro and C. Heejin, "Building hourly thermal load prediction using an indexed ARX model," Energy and Buildings, vol. 54, p. 225-233, 2012.

[6] M. Jingran, Q. Joe, S. Timothy and X. Peng, "Demand reduction in building energy systems based on economic model predictive control," Chemical Engineering Science, vol. 67, no. 1, p. 92-100, 2012.

[7] ESP-r. UniversityofStrathclyde., [Online]. Available: http://www.esru.strath.ac.

[8] "International Organization for Standardization - $\quad$ ISO 13790:2008," [Online]. Available: https://www.iso.org/standard/41974.html.

[9] K. J. Astrom, "Stochastic process," in Introduction to stochastic control theory, 2006, p. 307.

[10] L. Ljung, "System Identification and data analysis," in System Identification theory for the user, 1999, p. 315. 
[11] D. B. Crawley, L. K. Lawrie, F. C. Winkelmann, W. F. Buhl, Y. J. Huang, C. O. Pedersen and J. Glazer, "EnergyPlus: creating a new-generation building energy simulation program," Energy and Buildings, vol. 33, no. 4, p. 319-331, 2001.

[12] E. Bonnema, M. Leach and S. Pless, "Technical Support Document: Development of the Advanced Energy Design Guide for Large Hospitals - 50\% Energy Savings," National Renewable Energy Laboratory (NREL), Denver West, 2013.

[13] U.S. Department of Energy's (DOE) Building Technologies Office (BTO) and National Renewable Energy Laboratory (NREL), "«Energy Plus»," 2015. [Online]. Available: https://energyplus.net/.

[14] M. Deru, K. Field, D. Studer, K. Benna, B. Griffith and P. Torcellini, "Commercial Reference Building Models of the National Building Stock," «U.S. Department of Energy - National Renewable Energy Laboratory, Colorado, 2011.

[15] "Guide to Determining Climate Regions by County," Building America, 2010. 